\title{
Decavanadate induces mitochondrial membrane depolarization and inhibits oxygen consumption
}

\author{
S.S. Soares ${ }^{a}$, C. Gutiérrez-Merino ${ }^{b}$, M. Aureliano ${ }^{a, *}$ \\ ${ }^{a}$ Centro de Ciências do Mar (CCMar), Faculdade de Ciências e Tecnologia, Universidade do Algarve, Campus de Gambelas, $8005-139$ Faro, Portugal \\ ${ }^{\mathrm{b}}$ Grupo de Bioenergética en Neuronas y Miocitos, Departamento de Bioquímica y Biología Molecular, Facultad de Ciencias, \\ Universidad de Extremadura, Av. Elvas s/n, 06071 Badajoz, Spain
}

Received 4 December 2006; received in revised form 19 January 2007; accepted 24 January 2007

Available online 3 February 2007

\begin{abstract}
Decavanadate induced rat liver mitochondrial depolarization at very low concentrations, half-depolarization with $39 \mathrm{nM}$ decavanadate, while it was needed a 130 -fold higher concentration of monomeric vanadate $(5 \mu \mathrm{M})$ to induce the same effect. Decavanadate also inhibits mitochondrial repolarization induced by reduced glutathione in vitro, with an inhibition constant of $1 \mu \mathrm{M}$, whereas no effect was observed up to $100 \mu \mathrm{M}$ of monomeric vanadate. The oxygen consumption by mitochondria is also inhibited by lower decavanadate than monomeric vanadate concentrations, i.e. $50 \%$ inhibition is attained with $99 \mathrm{nM}$ decavanadate and $10 \mu \mathrm{M}$ monomeric vanadate. Thus, decavanadate is stronger as mitochondrial depolarization agent than as inhibitor of mitochondrial oxygen consumption. Up to $5 \mu \mathrm{M}$, decavanadate does not alter mitochondrial NADH levels nor inhibit neither $\mathrm{F}_{\mathrm{O}} \mathrm{F}_{1}$-ATPase nor cytochrome $c$ oxidase activity, but it induces changes in the redox steady-state of mitochondrial b-type cytochromes (complex III). NMR spectra showed that decameric vanadate is the predominant vanadate species in decavanadate solutions. It is concluded that decavanadate is much more potent mitochondrial depolarization agent and a more potent inhibitor of mitochondrial oxygen consumption than monomeric vanadate, pointing out the importance to take into account the contribution of higher oligomeric species of vanadium for the biological effects of vanadate solutions.
\end{abstract}

(C) 2007 Elsevier Inc. All rights reserved.

Keywords: Decavanadate; Vanadate; Mitochondria; Mitochondrial oxygen consumption; Mitochondrial depolarization

\section{Introduction}

Most of the toxicological studies of vanadate in biological systems do not take in consideration the contribution of vanadate oligomers, such as the decameric vanadate species $\left(\mathrm{V}_{10}\right)$. Decameric vanadate, composed by fused $\mathrm{V}(\mathrm{V})$ octahedra, has an ellipsoid like structure with a major and minor axis of approximately 7 and $6 \AA$, respectively [1]. In previous studies [2-8], we have demonstrated that

\footnotetext{
${ }^{*}$ Corresponding author. Tel.: +351 289800 900x7643; fax: +351 289 819403.

E-mail addresses: sssoares@ualg.pt (S.S. Soares), carlosgm@unex.es (C. Gutiérrez-Merino), maalves@ualg.pt (M. Aureliano).
}

once formed in aqueous solutions decameric vanadate decomposition is slow enough to allow studying differential effects between decameric and monomeric vanadate not only in vitro but also in vivo. Furthermore, decameric vanadate is stabilized upon interaction with cytoskeleton and membrane proteins, while it affects calcium translocation by the sarcoplasmic reticulum calcium pump and it prevents actin polymerization [9].

Vanadate is known to affect mitochondrial respiration by altering electron transfer between complexes III and IV [10]. Several studies have associated vanadium toxicity with its capacity to induce the formation of reactive oxygen species (ROS), probably by interacting with mitochondrial redox centres $[11,12]$. Along this line of thinking, DeMaster and Mitchell [10] pointed out that vanadate blocked electron 
transfer through the respiratory chain between cytochrome $b_{1}$ and cytochrome $c$, which caused inhibition of the oxidation of NADH-linked substrates and succinate $[13,14]$. Mitochondrial succinate dehydrogenase had also been reported to be inhibited by vanadium (V) ions [15], as well as the ATP-dependent succinyl-CoA synthetase (A-SCS) from rat brain mitochondria [16,17]. Studies involving other vanadate species, instead of only monomeric vanadate $\left(\mathrm{V}_{1}\right)$, have shown that decavanadate: (i) stimulates oxidation of NADH by rat erythrocyte plasma membrane $[18,19]$ and by rat liver microsomes [20,21]; (ii) enhances cytochrome $c$ reduction [22]; (iii) exhibits $\alpha$-adrenergic agonist activity in rat aortic rings [23]; and (iv) is reduced by $\mathrm{NADP}^{+}$-specific isocitrate dehydrogenase (IDH) [22].

As the effects of decameric vanadate on mitochondrial membrane potential and oxygen consumption have not been described, its contribution to the impairment of mitochondrial function associated with vanadium citotoxicity (Soares et al., unpublished results) is still an unresolved issue. This work addresses these points using rat hepatic mitochondria, aiming to elucidate the relative sensitivity of mitochondrial functions to decameric and monomeric vanadate. It is shown for the first time that decameric vanadate is a very strong mitochondrial depolarizing agent and also a potent inhibitor of mitochondrial oxygen consumption.

\section{Materials and methods}

\subsection{Vanadate solutions}

Metavanadate stock solution $(50 \mathrm{mM}, \mathrm{pH} 6.7)$ was prepared from ammonium metavanadate $\left(\mathrm{NH}_{4} \mathrm{VO}_{3}\right)$. Decavanadate stock solution was obtained by adjusting the $\mathrm{pH}$ of the former solution to 4.0 [24]. Vanadate oligomers composition of decavanadate and metavanadate solutions upon dilution into the mitochondrial respiration buffer (0.2 $\mathrm{M}$ sucrose, $5 \mathrm{mM} \mathrm{KH}_{2} \mathrm{PO}_{4}, 10 \mathrm{mM} \mathrm{KCl}, 5 \mathrm{mM} \mathrm{MgCl}_{2}$ and $10 \mathrm{mM}$ Tris $-\mathrm{HCl}, \mathrm{pH} 7.4$ plus $5 \mathrm{mM}$ pyruvate and $0.5 \mathrm{mM}$ malate), in the absence or in the presence of $5 \mathrm{mM}$ glutathione $(\mathrm{GSH})$, was measured by ${ }^{51} \mathrm{~V}$ nuclear magnetic resonance spectroscopy in a Bruker AM-400 spectrometer at $105.2 \mathrm{MHz}$ equipped with a $5-\mathrm{mm}$ multinuclear inverse probe, by using a $90^{\circ}$ pulse Fourier transform technique, as previously reported $[4,7,8]$.

\subsection{Animals}

Adult (3-month-old) male rats (Rattus norwegicus), weighing $200-250 \mathrm{~g}$, from an inbred Wistar strain were obtained from the Animal Services of the University of Extremadura, Badajoz (Spain). Animals were provided within a standard chow with free access to water and food. Animals were fasted overnight with a free access to water before sacrificed. All the experiments on animals follow the National Research Council's guide for the care and use of laboratory animals.

\subsection{Experimental procedures}

\subsubsection{Mitochondria isolation}

Mitochondria were isolated from rat liver by differential centrifugation, as described by Johnson and Lardy [25]. Mitochondria samples were aliquoted and stored at $-80^{\circ} \mathrm{C}$, immediately after their preparation in order to prevent in vitro aging, and used within 2 weeks. Protein concentration was determined with the Bradford's assay [26], using bovine serum albumin as protein standard. Rat hepatic mitochondria have succinate dehydrogenase and $\mathrm{F}_{\mathrm{O}} \mathrm{F}_{1}$-ATPase activities of $2120 \pm 453$ and $1115 \pm 64$ $\mathrm{nmol} / \mathrm{min} / \mathrm{mg}$ protein, respectively, values that falls within the range reported for these enzymes activities in mammalian mitochondria [27].

\subsubsection{Mitochondrial enzyme activities}

Succinate dehydrogenase (SDH) activity was measured at $37^{\circ} \mathrm{C}$ from potassium ferricyanide reduction [28]. $\mathrm{F}_{\mathrm{O}} \mathrm{F}_{1}$-ATPase activity was measured spectrophotometrically using the coupled enzyme pyruvate kinase/lactate dehydrogenase assay [29]. Vanadate solutions effects on mitochondrial $\mathrm{F}_{\mathrm{O}} \mathrm{F}_{1}$-ATPase activity was assayed, with decameric $\left(\mathrm{V}_{10}\right)$ or monomeric $\left(\mathrm{V}_{1}\right)$ vanadate species up to $20 \mu \mathrm{M}$ (total vanadium), in order to avoid the nonenzymatic NADH oxidation, observed in the presence of vanadium concentrations above $50 \mu \mathrm{M}$ (data not shown).

Decavanadate and metavanadate effects on mitochondrial cytochrome $c$ oxidase activity was analysed by the spectroscopic method of Smith [30]. The rate of oxidation of cytochrome $c$ was measured by following the decrease in the absorbance of its $\alpha$-band at $550 \mathrm{~nm}$ [31]. The standard reaction mixture containing $10 \mathrm{mM}$ phosphate buffer (pH 7.0) plus $14 \%$ ferrocytochrome $c$ and the absorbance change at $550 \mathrm{~nm}$ was measured at $37^{\circ} \mathrm{C}$, in the absence or in the presence of vanadate, after addition of $200 \mu \mathrm{g}$ mitochondria protein per $\mathrm{ml}$.

\subsubsection{Measurement of mitochondrial membrane potential}

Mitochondrial membrane potential was monitored using 5,5',6,6'-tetrachloro-1,1',3,3'-tetraethylbenzimidazolcarbocyanine iodide (JC-1), a fluorescent indicator of membrane potential [32].

Mitochondria $(15 \mu \mathrm{g}$ protein $/ \mathrm{ml})$ were loaded with $0.6 \mu \mathrm{M} \mathrm{JC}-1$ by incubation at $37^{\circ} \mathrm{C}$ for $15 \mathrm{~min}$ [33] and fluorescence experiments were performed under continuous stirring with a Perkin-Elmer 650-40 fluorescence spectrophotometer (Perkin-Elmer, Foster City, CA, USA). JC-1 monomer (green) fluorescence was measured by excitation at $490 \mathrm{~nm}$ and recording the emission near $532 \mathrm{~nm}$. JC-1 aggregate (red) fluorescence was measured by excitation at $490 \mathrm{~nm}$ and recording the emission at $595 \mathrm{~nm}$. The effect of vanadate solutions on mitochondrial membrane potential was determined by adding different vanadate concentration up to $50 \mu \mathrm{M}$ (total vanadium). Assays were standardized with a known 
potent uncoupler of oxidative phosphorylation, $1 \mathrm{mM}$ 2,4( $\alpha$ )-Dinitrophenol (DNP). The ratio of JC-1 aggregate to monomer intensity was calculated and the degree of depolarization estimated (Eq. (1)). The value of the ratio (F595/F532) for monomeric JC-1, which corresponds to totally depolarized mitochondria, was $1.52 \pm 0.47$. An increase in this ratio is indicative of increase in membrane potential, whereas a decrease in the ratio is indicative of decrease in membrane potential [34]

Depolarization $(\%)=\frac{R_{\mathrm{t}}-R_{0}}{R_{0}-R_{+\mathrm{DNP}}} \times 100$

$R_{\mathrm{t}}=$ ratio of JC-1 aggregate to monomer intensity after incubation (60 $\mathrm{min}$ )

$R_{0}=$ initial ratio of JC- 1 aggregate to monomer intensity (time $=0 \mathrm{~min}$ )

$R_{+ \text {DNP }}=$ ratio of JC-1 aggregate to monomer intensity $1 \mathrm{~h}$ after DNP addition

\subsubsection{Determination of mitochondrial oxygen consumption}

Oxygen consumption of mitochondria was measured polarographically with a Hansatech Oxygen Electrode equipped with a Clark-type oxygen electrode and a potentiometric recorder. Respiration of freshly isolated rat hepatic mitochondria at a final concentration $2 \mathrm{mg} / \mathrm{ml}$ was measured at $37^{\circ} \mathrm{C}$, in the standard reaction mixture contained (in $\mathrm{mM}$ ): 250 sucrose, $5 \mathrm{KH}_{2} \mathrm{PO}_{4}, 10 \mathrm{KCl}, 5 \mathrm{MgCl}_{2}$, 10 Tris $-\mathrm{HCl}(\mathrm{pH} 7.4)$ and supplemented with the following substrate combination: $0.5 \mathrm{mM}$ malate plus $5 \mathrm{mM}$ pyruvate. Respiration rates were measured in the absence and presence of $200 \mu \mathrm{M}$ ADP. $V_{10}$ effects on mitochondrial respiration were assayed upon incubation with vanadate concentrations of both vanadate stock solutions below $25 \mu \mathrm{M}$ (total vanadium). At the end of each run, an inhibitor of the mitochondrial electron transport chain $-40 \mu \mathrm{M}$ rotenone was added and the new rate of respiration measured. In the presence of rotenone, no oxygen consumption was obtained. The oxygen concentration in buffer was $219 \mathrm{nmol}$ of $\mathrm{O}_{2}$ per ml after standard calibration in water at $37{ }^{\circ} \mathrm{C}$. Oxygen consumption rates were expressed as nmol O/ $\mathrm{min} / \mathrm{mg}$ protein. Respiratory control ratio, as described by Chance and Williams [35], and ADP/O ratio were calculated as previously reported [36].

\subsubsection{Measurement of NADH content in mitochondria}

NADH content in isolated mitochondria exposed to vanadate concentrations up to $20 \mu \mathrm{M}$ (total vanadium), was determined through fluorimetric measurement of NADH in the neutralized alkaline mitochondrial extracts [37]. Fluorescence signals were recorded ( $\lambda$ excitation: $340 \mathrm{~nm} ; \lambda$ emission: $460 \mathrm{~nm})$ in a medium containing: $0.1 \mathrm{M}$ phosphate plus $0.1 \mathrm{M} \mathrm{KCl}$ ( $\mathrm{pH} 7.5), 1 \mathrm{mM}$ pyruvate and $1.375 \mathrm{IU}$ lactate dehydrogenase, and the NADH concentration was calculated using a fluorescence calibration curve obtained with known concentrations of this pyridine nucleotide.

\subsubsection{Reactive oxygen species production}

Vanadate effects on reactive oxygen species (ROS) production, namely superoxide anion $\left(\mathrm{O}_{2}^{--}\right)$production, was measured at $\mathrm{pH} 7.4$ and $37^{\circ} \mathrm{C}$ using the fluorescent dye dihydroethidium (DHE), as in Budd et al. [38]. The effect of an electron donor (NADH) on ROS production was tested separately in the presence and absence of vanadate (concentrations up to $50 \mu \mathrm{M}$ total vanadium). $\mathrm{O}_{2}^{--}$production was calculated from $10 \mu \mathrm{M}$ DHE fluorescence observed ( $\lambda$ excitation: $473 \mathrm{~nm} ; \lambda$ emission: $600 \mathrm{~nm}$ ) in presence of $0.5 \mathrm{mM}$ malate plus $5 \mathrm{mM}$ pyruvate or $250 \mu \mathrm{M}$ NADH.

\subsubsection{Cytochrome b redox state}

The overall spectrum of mitochondria was acquired by differential spectroscopy in a Hewlett Packard 8451 A diode array spectrophotometer, a single-beam, microprocessor-controlled spectrophotometer. The absorbance readings at all wavelengths of the overall spectrum (every $2 \mathrm{~nm}$ from 400 to $600 \mathrm{~nm}$ ) were obtained simultaneously. The incubation medium contained mitochondrial respiration buffer (Section 2.1), $0.5 \mathrm{mM}$ malate plus $5 \mathrm{mM}$ pyruvate and $1 \mathrm{mg}$ mitochondria protein per $\mathrm{ml}$. The electron chain spectrum and its redox changes upon incubation with decavanadate or metavanadate solutions were compared with a control situation (in the absence of vanadate).

\subsection{Statistical analysis}

All parameters studied are present as average and standard deviation of measurements taken at least in three separate experiments. Statistical significance of the data was calculated by Mann-Whitney non-parametric test. Differences from control were considered significant at $P<0.05$.

\section{Results and discussion}

\subsection{Effect of decavanadate on mitochondrial membrane potential}

In the absence of GSH the membrane potential remains stable for 10-15 min and then slowly decays (Fig. 1a), thus, allowing to determine the effects of decameric $\left(\mathrm{V}_{10}\right)$ and monomeric $\left(\mathrm{V}_{1}\right)$ vanadate on mitochondrial membrane potential. Fig. $1 \mathrm{~b}$ shows that $10 \mathrm{~min}$ exposure to increasing vanadate concentrations leads to increasing mitochondrial depolarization. $\mathrm{V}_{10}$ induced mitochondrial depolarization in rat hepatic mitochondria at very low concentrations with an $\mathrm{IC}_{50}$ of $38.7 \pm 10.2 \mathrm{nM}$, while $5.4 \pm 2.5 \mu \mathrm{M} \mathrm{V}$ was needed to induce a $50 \%$ depolarization in rat liver mitochondria.

\subsubsection{Decavanadate effect on GSH-induced mitochondrial membrane repolarization in respiration buffer}

Addition of a physiological concentration of GSH $(5 \mathrm{mM})$ to the mitochondria respiration buffer after $60 \mathrm{~min}$, i.e. to depolarized mitochondria, induced mitochondrial repolarization in vitro with a half-time of $\approx 5 \mathrm{~min}$, reaching 

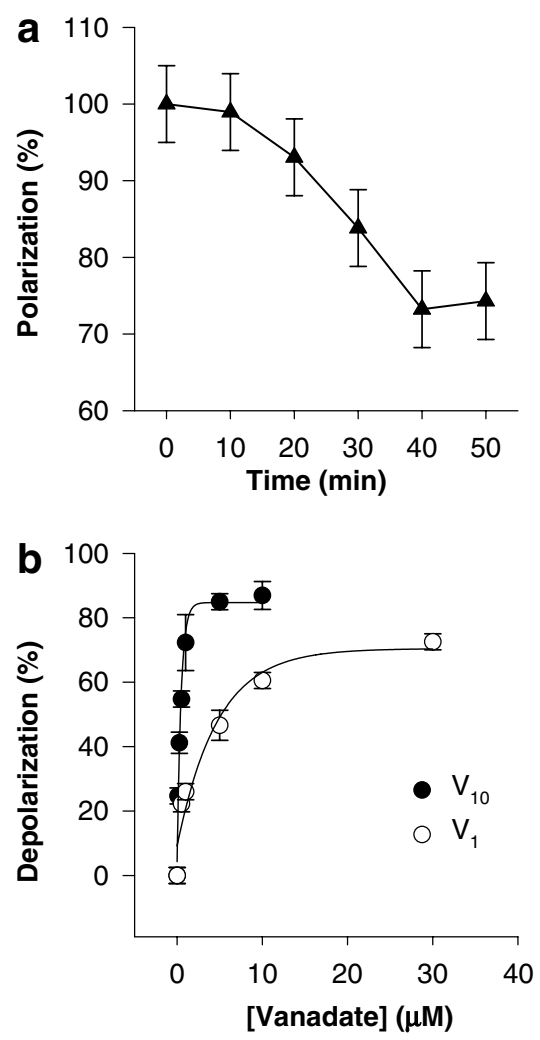

Fig. 1. Mitochondrial membrane depolarization by decameric $\left(\mathrm{V}_{10}\right)$ and monomeric $\left(\mathrm{V}_{1}\right)$ vanadate species. Time-induced mitochondrial membrane depolarization (a) in the absence of a physiological glutathione (GSH) concentration; $\mathrm{V}_{10^{-}}$(solid circles) and $\mathrm{V}_{1}$-induced (open circles) mitochondrial membrane depolarization $(\%)$ on rat liver mitochondria $(15 \mu \mathrm{g}$ protein $/ \mathrm{ml}$ ), in the presence of $5 \mathrm{mM} \mathrm{GSH}$ (b). The assay was performed at $37^{\circ} \mathrm{C}$, in a reaction medium containing the corresponding mitochondrial isolation buffer $(250 \mathrm{mM}$ sucrose; $5 \mathrm{mM}$ Tris $\mathrm{pH} 7.4$ and $1 \mathrm{mM}$ EGTA) supplemented with $150 \mathrm{mM} \mathrm{KCl}, 10 \mathrm{mM}$ Tris $\mathrm{pH} 7.4,0.5 \mathrm{mM}$ malate plus $5 \mathrm{mM}$ pyruvate and $0.6 \mu \mathrm{M} 5,5^{\prime}, 6,6^{\prime}$-tetrachloro-1,1',3,3'tetraethylbenzimidazolcarbocyanine iodide (JC-1), a fluorescent indicator of membrane potential. Values are present as means $\pm \mathrm{SD}(n=3)$.

a steady-state $\approx 10$ min after GSH addition (Fig. 2). Besides inducing membrane repolarization, GSH confers stability of the mitochondrial membrane potential with a half-life time of $\approx 90 \mathrm{~min}$ (data not shown).

From steady-state values of the control $(\approx 2.75), \mathrm{V}_{10}$ $(\approx 2.0)$ and $\mathrm{V}_{1}(\approx 3.0)$ we determined the effects induced by the vanadate solutions on membrane repolarization, considering the approx. basal value of 1.25 observed at time zero, for the addition of GSH. In this sense, for $1 \mu \mathrm{M} \mathrm{V} \mathrm{V}_{10}$ we obtained an inhibition of almost $50 \%$, whereas in the presence of $100 \mu \mathrm{M} \mathrm{V}$ the mitochondrial repolarization was stimulated by $\approx 10 \%$ (Fig. 2).

\subsection{Effect of decavanadate on mitochondrial oxygen consumption}

With pyruvate plus malate, the basal respiration rate of our preparations of rat hepatic mitochondria was 39 and $20 \mathrm{ng}$ atom $\mathrm{O} / \mathrm{min} / \mathrm{mg}$ protein for State 3 and 4, respec-

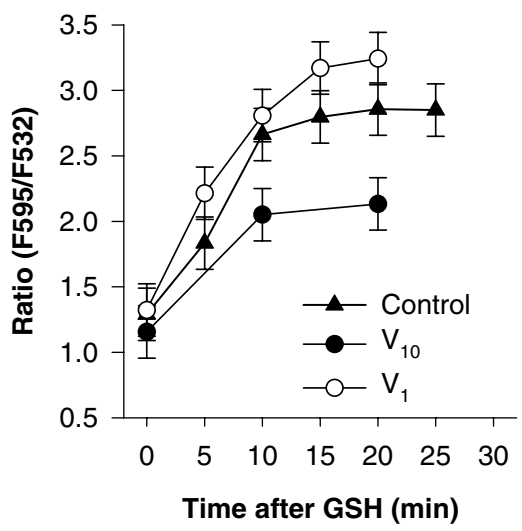

Fig. 2. Kinetics of mitochondrial membrane repolarization. Kinetics of mitochondrial membrane repolarization with physiological glutathione (GSH) concentration $(5 \mathrm{mM})$ (solid triangles); GSH-induced repolarization after mitochondrial membrane depolarization by $1 \mu \mathrm{M}$ decameric vanadate $\left(\mathrm{V}_{10}\right)$ (solid circles) or $100 \mu \mathrm{M}$ monomeric vanadate $\left(\mathrm{V}_{1}\right)$ (open circles) in respiration buffer minus GSH. Repolarization was monitored at $37^{\circ} \mathrm{C}$ in $250 \mathrm{mM}$ sucrose, $15 \mathrm{mM}$ Tris $\mathrm{pH} 7.4,1 \mathrm{mM}$ EGTA, $150 \mathrm{mM}$ $\mathrm{KCl}, 0.5 \mathrm{mM}$ malate plus $5 \mathrm{mM}$ pyruvate, $15 \mu \mathrm{g}$ hepatic mitochondria protein $/ \mathrm{ml}$ and $0.6 \mu \mathrm{M}$ JC-1 membrane potential fluorescent indicator. Values are present as means $\pm \mathrm{SD}(n=3)$.

tively. It was observed that $\mathrm{V}_{10}$ inhibits mitochondrial respiration at State 3 (ADP-stimulated) as shown by a decrease in oxygen consumption measured in intact liver mitochondria (Fig. 3a). $V_{10}$ is nearly 100 -fold more potent than $\mathrm{V}_{1}$ as inhibitor of oxygen consumption in hepatic mitochondria, as shown by their $\mathrm{IC}_{50}$ values, $98.5 \pm 5.1$ $\mathrm{nM}$ for $\mathrm{V}_{10}$ and $9.7 \pm 1.4 \mu \mathrm{M}$ for $\mathrm{V}_{1}$ (Fig. 3a).

Both vanadate solutions promote mitochondrial respiration inhibition without uncoupling mitochondria, as the respiratory control ratio (RCR) was not affected (Fig. 3b). The RCR values for rat liver coupled mitochondria respiring on pyruvate and malate were $5.1 \pm 0.1$, in the absence or presence of both vanadates species (Fig. 3b). These results are in good agreement with those reported in [10], where there was found no uncoupling of oxidative phosphorylation in intact rat liver mitochondria and a small apparent increase in $\mathrm{ADP} / \mathrm{O}$ rates, due to an inhibition of adenylate kinase activity by $\mathrm{V}_{10}(1 \mathrm{mM})$. It is to be noted that our results leads to ADP/O ratios for pyruvate and malate of $2.4 \pm 0.7$, both in the absence or presence of $\mathrm{V}_{10}$ or $\mathrm{V}_{1}$, a value which is close to the theoretical value of $3[36]$.

\subsection{Decavanadate effects on mitochondrial $F_{O} F_{1}$-ATPase activity, NADH levels and reactive oxygen species production}

Rat hepatic mitochondria $\mathrm{F}_{\mathrm{O}} \mathrm{F}_{1}$-ATPase exhibited a basal control activity of $1115 \pm 64 \mathrm{nmol} / \mathrm{min} / \mathrm{mg}$ protein. Up to $20 \mu \mathrm{M}$, no effects were observed for $\mathrm{V}_{10}$ or $\mathrm{V}_{1}$ on this mitochondrial ATPase activity, in agreement with several studies using higher vanadate concentrations $(100 \mu \mathrm{M}$ total 

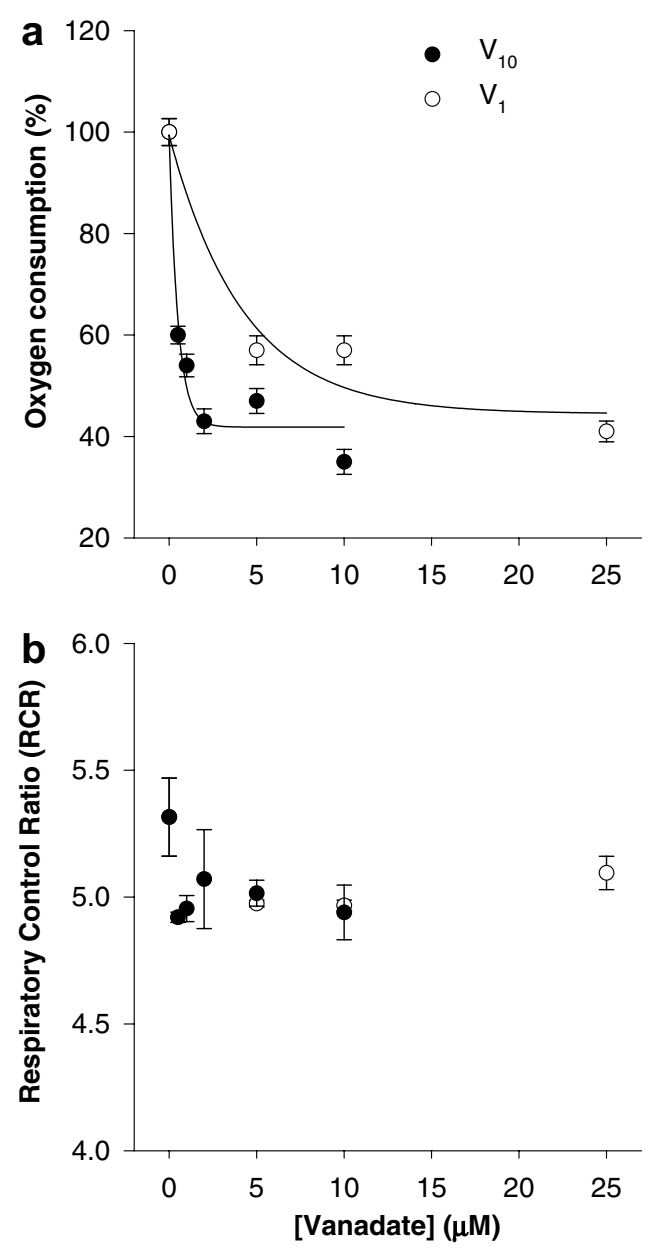

Fig. 3. Decameric vanadate $\left(\mathrm{V}_{10}\right)$ and monomeric vanadate $\left(\mathrm{V}_{1}\right)$ inhibitory effects on mitochondrial respiration measured with an oxygen electrode. Effect of $\mathrm{V}_{10}$ (solid circles) and $\mathrm{V}_{1}$ (open circles) (up to $25 \mu \mathrm{M}$ total vanadium, namely $2.5 \mu \mathrm{M} \mathrm{V}_{10}$ ) on rat liver respiring mitochondria (2 $\mathrm{mg}$ protein $/ \mathrm{ml}$ ) on pyruvate plus malate. Oxygen consumption (\%) (a) and respiratory ratio control (RCR) (b) on hepatic intact mitochondria were recorded in mitochondrial respiration buffer containing $0.2 \mathrm{M}$ sucrose, $5 \mathrm{mM} \mathrm{KH}_{2} \mathrm{PO}_{4}, 10 \mathrm{mM} \mathrm{KCl}, 5 \mathrm{mM} \mathrm{MgCl} 2$ and $10 \mathrm{mM}$ Tris $\mathrm{pH} 7.4$, to a final volume of $2 \mathrm{ml}(5 \mathrm{mM}$ pyruvate plus $0.5 \mathrm{mM}$ malate were added as substrate). Values are present as means $\pm \mathrm{SD}(n=3)$.

vanadium) $[39,40]$. NADH levels in mitochondria were also not affected by the vanadate solutions.

Additionally, both $\mathrm{V}_{10}$ and $\mathrm{V}_{1}$ had no effect on reactive oxygen species (ROS) production, namely $\mathrm{O}_{2}^{-}$, on rat hepatic mitochondria (Fig. 4a), except when NADH is used as an electron transfer chain substrate (Fig. 4b). Under the latter experimental conditions, $\mathrm{V}_{10}$ decreases $\mathrm{O}_{2}^{-}$production by $40 \%(5 \mu \mathrm{M})$ whereas 10 -fold $\mathrm{V}_{1}(50 \mu \mathrm{M})$ is need to induce a similar effect. This decrease in $\mathrm{O}_{2}^{--}$formation is, at least in part, due to the observed inhibition in mitochondrial respiration, once it was proved that $\mathrm{O}_{2}^{-}$originating from respiring mitochondria is a stoichiometric precursor of mitochondrial hydrogen peroxide $\left(\mathrm{H}_{2} \mathrm{O}_{2}\right)$.

Recently, it has been described that in rat brain mitochondria even a very small decrease of mitochondrial membrane potential, which decreases mitochondrial res-
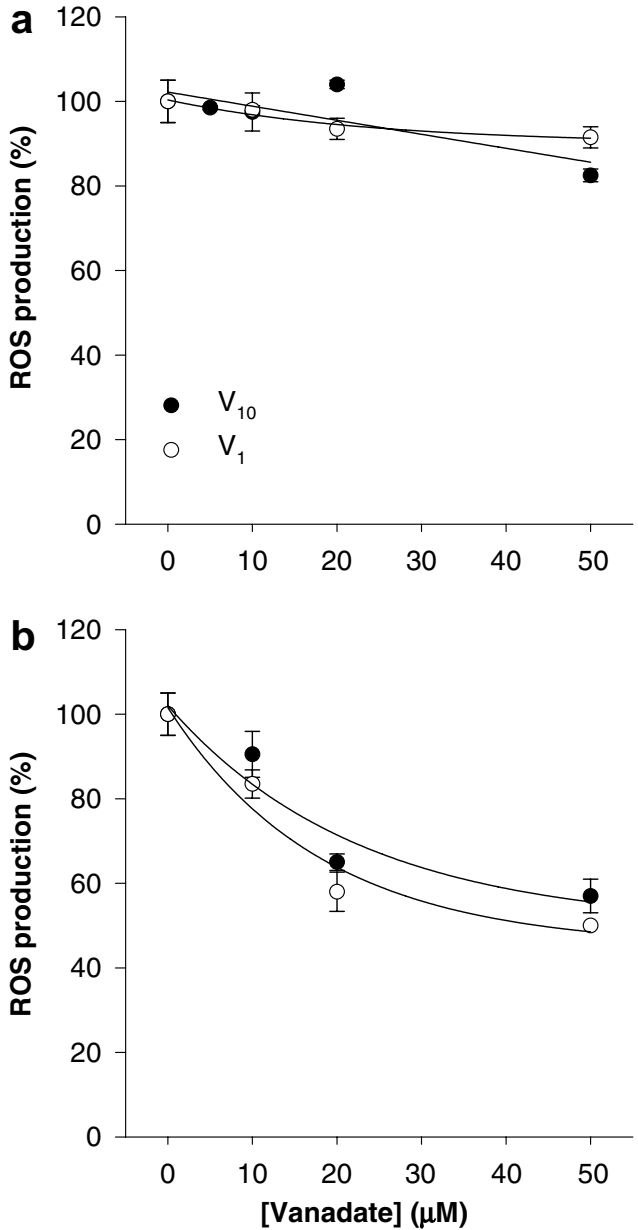

Fig. 4. Rate of reactive oxygen species (ROS) production, namely superoxide anion $\left(\mathrm{O}_{2}^{-}\right)$, upon exposure to decameric $\left(\mathrm{V}_{10}\right)$ and monomeric $\left(\mathrm{V}_{1}\right)$ vanadate species. Effect of $\mathrm{V}_{10}$ (solid circles) and $\mathrm{V}_{1}$ (open circles) (up to $50 \mu \mathrm{M}$ total vanadium) on $\mathrm{O}_{2}^{--}$production (\%) minus $\mathrm{NADH}(\mathrm{A})$ and in the presence of NADH (B) in rat liver mitochondria $(15 \mu \mathrm{g}$ protein $/ \mathrm{ml})$. The assay was performed at $37{ }^{\circ} \mathrm{C}$, in the presence of the corresponding mitochondrial isolation buffer $(250 \mathrm{mM}$ sucrose; $5 \mathrm{mM}$ Tris $\mathrm{pH} 7.4$ and $1 \mathrm{mM}$ EGTA) supplemented with $150 \mathrm{mM} \mathrm{KCl}, 10 \mathrm{mM}$ Tris $\mathrm{pH} 7.4$, $0.5 \mathrm{mM}$ malate plus $5 \mathrm{mM}$ pyruvate (a) or $250 \mu \mathrm{M}$ NADH (b) and $10 \mu \mathrm{M}$ dihydroethidium (DHE) fluorescent probe. Values are present as means $\pm \mathrm{SD}(n=3)$.

piration, results in a strong inhibition of ROS formation [41]. Therefore, ROS formation is also a function of mitochondrial membrane potential. Since $V_{10}$ strongly depolarized mitochondria, the capacity to produce $\mathrm{O}_{2}^{-}$ will be depressed and, in fact, the results obtained for $\mathrm{V}_{10}$ are fully consistent with this statement (Fig. 4b). Therefore, both $\mathrm{V}_{10}$-induced mitochondrial depolarization and decrease in mitochondrial oxygen consumption can account for its antioxidant effect, monitored as partial inhibition of ROS production.

\subsection{Characterization of vanadate solutions: NMR studies}

In order to precisely define what vanadate species are promoting the observed effects in isolated rat liver 
mitochondria, the vanadate species composition in vanadate solutions was analyzed by ${ }^{51} \mathrm{~V}$ NMR spectroscopy. It was observed that the spectra of decavanadate solution, after dilution in the mitochondrial respiration buffer (Section 2.1) - $5 \mathrm{mM}$ total vanadium, at $\mathrm{pH} 7.0$ - contained only decameric species once the three signals from $\mathrm{V}_{10}$, attributed to the three vanadium atoms of the decavanadate structure, as described elsewhere [24], are observed: $\mathrm{V}_{10 \mathrm{~A}}$ at $-516 \mathrm{ppm}, \mathrm{V}_{10 \mathrm{~B}}$ at $-499 \mathrm{ppm}$ and $\mathrm{V}_{10 \mathrm{C}}$ at $-425 \mathrm{ppm}$ (Fig. 5a). Conversely, in the metavanadate solution (Fig. $5 \mathrm{c}$ ), $5 \mathrm{mM}$ total vanadium, were detected mono$\left(\mathrm{V}_{1}\right)$, di- $\left(\mathrm{V}_{2}\right)$ and also tetrameric $\left(\mathrm{V}_{4}\right)$ vanadate species, respectively, at $-561 \mathrm{ppm},-575 \mathrm{ppm}$ and at $-579 \mathrm{ppm}$. Two new vanadate signals were clearly identified in the ${ }^{51} \mathrm{~V}$ NMR spectra of vanadate solution diluted in mitochondrial respiration buffer (Fig. $5 \mathrm{c}$ ): these bound vanadate signals observed at $-555 \mathrm{ppm}(\mathrm{C} 1)$ and $-540 \mathrm{ppm}$ (C2) are due to the presence of sucrose in the medium, being $\mathrm{C} 1$ and $\mathrm{C} 2$ due to complexes of vanadate with geometric isomers of sucrose [42].

Millimolar GSH concentrations, the concentration range of GSH reported for most mammalian tissues, is known to reduce millimolar vanadate to vanadium(IV) at a physiological $\mathrm{pH} 7$ [43]. In the presence of $5 \mathrm{mM} \mathrm{GSH}$, used in the mitochondrial membrane potential studies, $\mathrm{V}_{10}$ signals suffer a decrease in intensity without broadening of the peaks (Fig. 5b). This decrease in the intensity of the decameric vanadate signals is due to $\mathrm{V}_{10}$ deoligomerization since it was observed that GSH induces it decomposition (not shown). In fact, a small peak at $-561 \mathrm{ppm}$, can be observed upon addition of $5 \mathrm{mM}$ GSH (Fig. 5d). The eventual presence of vanadyl paramagnetic species in solution would induce a broadening of NMR $V_{10}$ signals besides an increase of the signal/noise ratio (that was not observed, see Fig. 5b). At physiological $\mathrm{pH}$, vanadate NMR signals observed for the metavanadate solution remain unchanged upon addition of GSH to the medium (Fig. 5d), although it has been described that in the presence of GSH, vanadate is reduced to vanadyl and it becomes bound to haemoglobin [43].

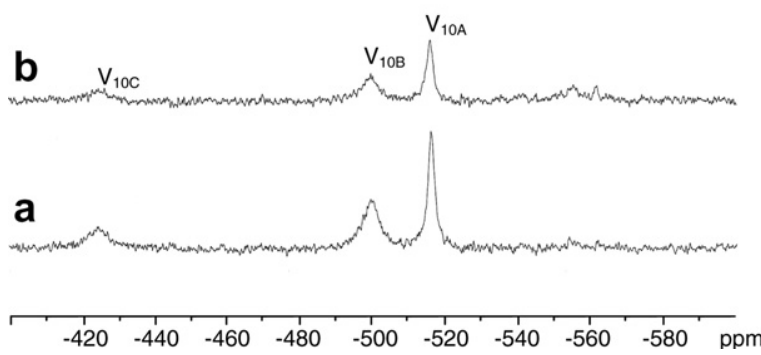

In the presence of $1 \mathrm{mg} / \mathrm{ml}$ mitochondria, neither the concentration of the different vanadate species nor the ratio between vanadate oligomers in both solutions were changed (data not shown). Therefore, vanadate species do not disappear under the conditions used for the kinetic studies reported in this work, allowing correlating its in vitro effects on mitochondrial integrity and functionality. In contrast with metavanadate solutions, which contain labile oxovanadates interconverting each other within the milliseconds time scale, decameric vanadate present in decavanadate solutions has very slow decomposition kinetics upon dilution.

The kinetics of deoligomerization, assessed by measurements of the absorption at $400 \mathrm{~nm}$, is a first order kinetics [8], with a half-life time up to $3 \mathrm{~h}$ (measured at $37^{\circ} \mathrm{C}$ with $100 \mu \mathrm{M}$ decameric vanadate species in mitochondrial respiration buffer). Therefore, at the $\mathrm{V}_{10}$ concentrations used in the enzymatic studies the decavanadate solutions contain decameric species whereas metavanadate solutions up to $100 \mu \mathrm{M}$ mostly contain monomeric vanadate species, as described elsewhere [42].

\subsection{Decavanadate effects on complex III}

\subsubsection{Decavanadate effects on cytochrome c oxidase}

To experimentally test the possibility that the mechanism of $\mathrm{V}_{10}$-induced inhibition of the electron transport chain could be due to inhibition of complex III, at first we measured the effect of $\mathrm{V}_{10}$ on the redox state of ferrocytochrome $c$. It was observed that at $\mathrm{pH} 7.0$, either $\mathrm{V}_{10}$ or $\mathrm{V}_{1}$ did not induce changes on the redox state of purified ferrocytochrome $c$. Moreover, neither $\mathrm{V}_{10}$ nor $\mathrm{V}_{1}$ alter the cytochrome $c$ oxidase activity of rat liver mitochondria (measured as indicated in Section 2.1). These results are in good agreement with the major conclusion reached in Kalyani and Ramasarma [21], namely, that the oxidation of reduced cytochrome $c$ during vanadate-stimulated $\mathrm{NADH}$ oxidation required the presence of both vanadate and $\mathrm{H}_{2} \mathrm{O}_{2}$, since the latter oxidation is produced by the hydroxyl radicals formed in vanadate $/ \mathrm{H}_{2} \mathrm{O}_{2}$ mixtures.

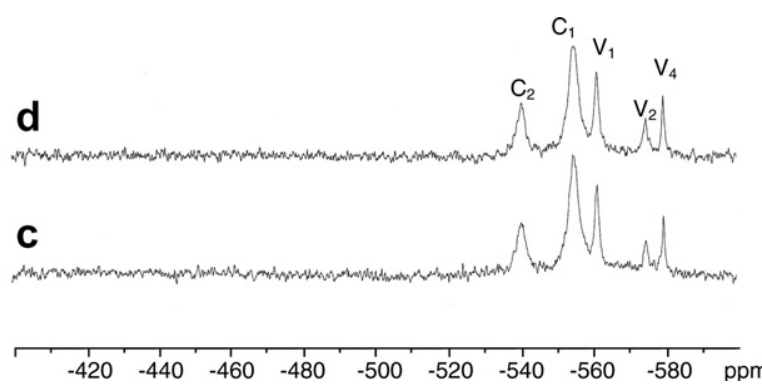

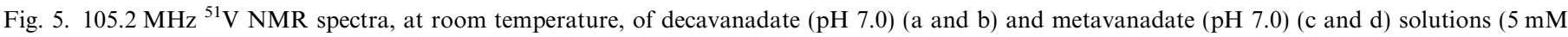

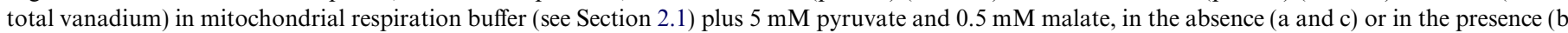

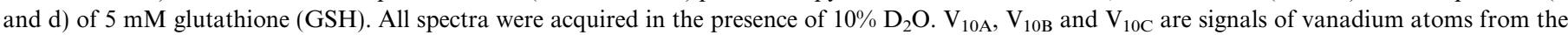

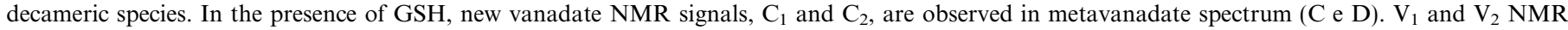

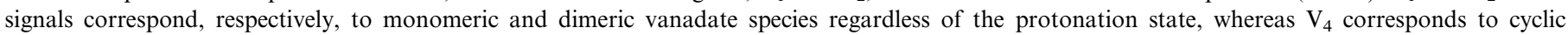
tetrameric vanadate species. $\mathrm{C}_{1}$ and $\mathrm{C}_{2}$ stand for sucrose:vanadate complexes. 


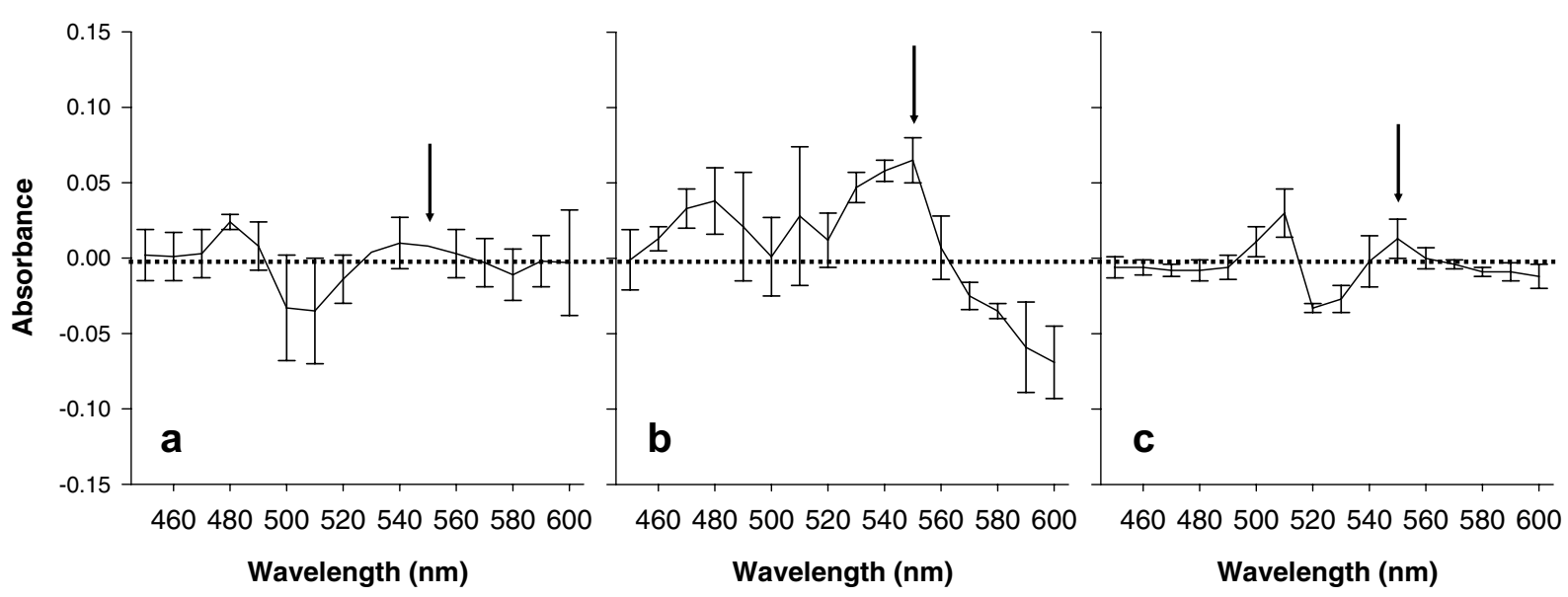

Fig. 6. Decameric vanadate $\left(\mathrm{V}_{10}\right)$-induced redox changes on cytochromes spectra of the respiratory chain. The figure shows the differential spectrum of rat liver mitochondria $(1 \mathrm{mg}$ protein $/ \mathrm{ml})$ in the presence of respiratory substrates $(5 \mathrm{mM}$ pyruvate $+0.5 \mathrm{mM}$ malate) minus the spectrum in the same buffer in the absence of respiratory substrates. All the spectra were recorded on a split beam spectrophotometer upon incubation with $20 \mu \mathrm{M}$ (total vanadium) $\mathrm{V}_{10}$ (b) or monomeric vanadate, $\mathrm{V}_{1}$ (c) on mitochondrial respiration buffer (see Section 2.1). In the presence of $\mathrm{V}_{10}$ (B) there are large absorbance changes in the wavelength range that monitors the redox state of mitochondrial cytochromes $b(500-550 \mathrm{~nm})$ with respect to control (a). The arrows point at the wavelengths reported for the absorbance peaks of mitochondrial cytochromes $b$ [46]. Values are present as means $\pm \operatorname{SD}(n=3)$.

\subsubsection{Decavanadate effect on cytochrome b}

Once excluded that $\mathrm{V}_{10}$-induced mitochondrial depolarization and inhibition of oxygen consumption can be rationalized in terms of inhibition of cytochrome oxidase, we considered the possibility that the redox state of mitochondrial cytochromes $b$ could be affected by decavanadate. To this end we recorded the effects of $V_{10}$ and $V_{1}$ ( $20 \mu \mathrm{M}$ total vanadium) on the differential spectrum of mitochondria in the presence and absence of the respiration substrates (pyruvate plus malate). The changes in the $500-550 \mathrm{~nm}$ wavelength range induced by $\mathrm{V}_{10}$ pointed out that the cytochrome $b$ redox state is altered by $\mathrm{V}_{10}$, but not with $\mathrm{V}_{1}$, suggesting that mitochondrial complex III (ubiquinol:cytochrome $c$ oxidoreductase) is a target for decameric vanadate (Fig. 6). Therefore, $V_{10}$ induces antimycin A-like inhibition (specific inhibitor of complex III) in mitochondria respiratory chain.

\section{Concluding remarks}

Previous in vivo studies allowed us to suggest that mitochondria is a subcellular target of vanadate when vanadium is administered as $\mathrm{V}_{10}$ [2,5-8]. In the present work, it is shown for the first time that $V_{10}$ is 10 to 100 -fold more potent than $\mathrm{V}_{1}$ as mitochondrial depolarization agent and as inhibitor of oxygen consumption by mitochondria. Moreover, $\mathrm{V}_{10}$-induced mitochondrial depolarization is observed at $\mathrm{V}_{10}$ concentrations lower than those required to produce a significant inhibition of oxygen consumption by mitochondria. As membrane hyperpolarization has been described to be an early mitochondrial response during apoptosis [44,45], these results suggest to explore the usefulness of $\mathrm{V}_{10}$ as an anti-apoptotic agent in future studies. These effects of $\mathrm{V}_{10}$ are likely due to $\mathrm{V}_{10}$-induced changes in the redox steady-state of cytochrome $b$ (complex III), as neither the mitochondrial NADH level, nor cytochrome oxidase, nor $\mathrm{F}_{\mathrm{O}} \mathrm{F}_{1}$-ATPase activities are significantly altered by $\mathrm{V}_{10}$. Furthermore, it is concluded that decameric vanadate strongly affects mitochondria bioenergetics through different toxicity mechanisms than monomeric vanadate.

\section{Abbreviations}

DHE dihydroethidium

DNP 2,4( $\alpha)$-dinitrophenol

GSH glutathione reduced form

$\mathrm{H}_{2} \mathrm{O}_{2}$ hydrogen peroxide

$\mathrm{IC}_{50}$ concentration that produced $50 \%$ of the effect on mitochondria membrane potential, on oxygen consumption or that inhibits $50 \%$ an enzyme activity

IU amount of enzyme that release $1 \mu$ mole of product per minute

JC-1 5, 5',6,6'-tetrachloro-1,1',3, $3^{\prime}$-tetraethylbenzimidazolcarbocyanine iodide

NADH $\beta$-nicotinamide adenine dinucleotide (reduced form)

$\mathrm{O}_{2}^{-} \quad$ superoxide anion

ROS reactive oxygen species

SDH succinate dehydrogenase

Tris tris(hydroxymethyl)aminomethane

$\mathrm{V}_{1} \quad$ orthovanadate or monomeric vanadate species

$\mathrm{V}_{10}$ decameric vanadate species

$\mathrm{V}_{2} \quad$ dimeric vanadate species

$\mathrm{V}_{4} \quad$ tetrameric vanadate species

\section{Acknowledgements}

This work was supported by the POCTI program financed through FEDER, research project 38191/QUI/ 
2001. S.S. Soares was supported by PhD Grant SFRH/ BD/8615/2002 from Portuguese Foundation for Science and Technology (FCT). The authors wish to gratefully acknowledge to A. Alonso (Grupo de Bioenergética en Neuronas y Miocitos, Depto. Bioquímica y Biología Molecular, Facultad de Ciencias, Universidad de Extremadura) her skilful technical assistance.

\section{References}

[1] D. Rehder, in: H. Sigel, A. Sigel (Eds.), Metal Ions in Biological Systems, vol. 31, Marcel Dekker, Inc., New York, 1995, pp. 1-43.

[2] M. Aureliano, N. Joaquim, A. Sousa, H. Martins, J.M. Coucelo, J. Inorg. Biochem. 90 (2002) 159-165.

[3] G. Borges, P. Mendonça, N. Joaquim, M. Aureliano, J.M. Coucelo, Arch. Environ. Contam. Toxicol. 45 (2003) 415-422.

[4] S.S. Soares, M. Aureliano, N. Joaquim, J.M. Coucelo, J. Inorg. Biochem. 94 (2003) 285-290.

[5] M. Aureliano, R.M.C. Gândara, J. Inorg. Biochem. 99 (2005) 979 985.

[6] R.M.C. Gândara, S.S. Soares, H. Martins, C. Gutiérrez-Merino, M. Aureliano, J. Inorg. Biochem. 99 (2005) 1238-1244.

[7] S.S. Soares, H. Martins, M. Aureliano, Arch. Environ. Contam. Toxicol. 50 (2006) 60-64.

[8] S.S. Soares, H. Martins, R.O. Duarte, J.J.G. Moura, J. Coucelo, C. Gutiérrez-Merino, M. Aureliano, J. Inorg. Biochem. 101 (2007) 8088.

[9] S. Ramos, M. Manuel, T. Tiago, R.M.C. Gândara, R.O. Duarte, J.J.G. Moura, C. Gutiérrez-Merino, M. Aureliano, J. Inorg. Biochem. 100 (2006) 1734-1743.

[10] E.G. DeMaster, R.A. Mitchell, Biochemistry 12 (1973) 3616-3621.

[11] X.G. Yang, X.D. Yang, L. Yuan, K. Wang, D.C. Crans, Pharm. Res. 21 (2004) 1026-1033.

[12] M. Valko, H. Morris, M.T. Cronin, Curr. Med. Chem. 12 (2005) 1161-1208

[13] J.Z. Byczkowski, L. Zychlinski, J. Tluczkiewicz, Int. J. Biochem. 10 (1979) 1007-1011.

[14] L. Zychlinski, J.Z. Byczkowski, Arch. Environ. Contam. Toxicol. 19 (1990) 138-142.

[15] J. Velours, A. Lavat, M. Guerin, B. Guerin, Biochimie 57 (1975) 975 978.

[16] J. Krivanek, L. Novakova, Gen. Physiol. Biophys. 10 (1991) 71-82.

[17] J. Krivanek, L. Novakova, Physiol. Res. 41 (1992) 345-350.

[18] S. Vijaya, F.L. Crane, T. Ramasarma, Mol. Cell. Biochem. 62 (1984) 175-185.

[19] P. Kalyani, T. Ramasarma, Arch. Biochem. Biophys. 297 (1992) 244 252.
[20] P. Kalyani, S. Vijaya, T. Ramasarma, Mol. Cell. Biochem. 111 (1992) 33-40.

[21] P. Kalyani, T. Ramasarma, Mol. Cell. Biochem. 121 (1993) 21-29.

[22] A.V. Rao, T. Ramasarma, Biochim. Biophys. Acta 1474 (2000) 321330.

[23] B.V. Venkataraman, H.N. Ravishankar, A.V. Rao, P. Kalyani, G. Sharada, K. Namboodiri, B. Gabor, T. Ramasarma, Mol. Cell. Biochem. 169 (1997) 27-36.

[24] M. Aureliano, V.M.C. Madeira, Biochim. Biophys. Acta 1221 (1994) 259-271.

[25] D. Johnson, H. Lardy, Meth. Enzymol. 10 (1967) 94-101.

[26] M. Bradford, Anal. Biochem. 72 (1976) 248-254.

[27] G.C. Monroy, M.E. Pullman, Meth. Enzymol. 10 (1967) 500-512.

[28] C. Veeger, D.V. DerVartanian, W.P. Zeylemaker, Meth. Enzymol. 12 (1969) 81-90.

[29] A. Cuenda, F. Henao, C. Gutiérrez-Merino, Eur. J. Biochem. 194 (1990) 663-670.

[30] L. Smith, Meth. Biochem. Anal. 2 (1955) 427-434.

[31] D.C. Wharton, A. Tzagoloff, Meth. Enzymol. 10 (1967) 245-250.

[32] M. Reers, T.W. Smith, L.B. Chen, Biochemistry 30 (1991) 4480-4486.

[33] S.T. Smiley, M. Reers, C. Mottola-Hartshorn, M. Lin, A. Chen, T.W. Smith, G.D. Steele, L.B. Chen, Proc. Natl. Acad. Sci. USA 88 (1991) 3671-3675.

[34] M.B. Troyan, V.R. Gilman, C.V. Gay, Exp. Cell Res. 233 (1997) 274 280.

[35] B. Chance, G.R. Williams, Adv. Enzymol. Relat. Subj. Biochem. 17 (1956) 65-134.

[36] K. Cain, D.N. Skilleter, in: K. Snell, B. Mullok (Eds.), Biochemical toxicological: a practical approach, IRL Press, Oxford, 1987, pp. 217 254

[37] F.J. Martin-Romero, Y. Gutiérrez-Martin, F. Henao, C. GutiérrezMerino, J. Fluoresc. 14 (2004) 17-23.

[38] S.L. Budd, R.F. Castilho, D.G. Nicholls, FEBS Lett. 415 (1997) $21-$ 24.

[39] B.J. Bowman, S.E. Mainzer, K.E. Allen, C.W. Slayman, Biochim. Biophys. Acta 512 (1978) 13-28.

[40] S.G. O'Neal, D.B. Rhoads, E. Racker, Biochem. Biophys. Res. Commun. 89 (1979) 845-850.

[41] T.V. Votyakova, I.J. Reynolds, J. Neurochem. 79 (2001) 266-277.

[42] M. Aureliano, V.M.C. Madeira, in: J.O. Nriagu (Ed.), Vanadium in the environment, Part 1, John Wiley \& Sons, Inc., New York, 1998, pp. 333-357.

[43] I.G. Macara, K. Kustin, L.C.C. Cantley Jr., Biochim. Biophys. Acta 629 (1980) 95-106.

[44] N. Zurgil, Y. Shafran, D. Fixler, M. Deutsch, Biochem. Biophys. Res. Commun. 290 (2002) 1573-1582.

[45] P. Matarrese, L. Gambardella, A. Cassone, S. Vella, R. Cauda, W. Malorni, J. Immunol. 170 (2003) 6006-6015.

[46] D. Feldman, W.W. Wainio, J. Biol. Chem. 235 (1960) 3635-3639. 